\title{
Comorbidities in Patients with Rheumatoid Arthritis and Their Association with Patient-reported Outcomes: Results of Claims Data Linked to Questionnaire Survey
}

\author{
Andres Luque Ramos (D), Imke Redeker, Falk Hoffmann, Johanna Callhoff, Angela Zink, \\ and Katinka Albrecht
}

ABSTRACT. Objective. To investigate the prevalence of comorbidities in a population-based cohort of persons with rheumatoid arthritis (RA) compared to matched controls and to examine their association with patient-reported outcomes in a survey sample.

Methods. Data of 96,921 persons with RA [International Classification of Diseases, 10th ed (ICD-10) M05/M06] and 484,605 age- and sex-matched controls without RA of a German statutory health fund were studied regarding 26 selected comorbidities (ICD-10). A self-reported questionnaire, comprising joint counts [(tender joint count (TJC), swollen joint count (SJC)], functional status (Hannover Functional Ability Questionnaire), effect of the disease (Rheumatoid Arthritis Impact of Disease), and well-being (World Health Organization 5-item Well-Being Index; WHO-5) was sent to a random sample of 6193 persons with RA, of whom 3184 responded. For respondents who confirmed their RA $(n=2535)$, associations between comorbidities and patient-reported outcomes were analyzed by multivariable linear regression.

Results. Compared to controls, all investigated comorbidities were more frequent in persons with RA (mean age 63 yrs, $80 \%$ female). In addition to cardiovascular risk factors, the most common were osteoarthritis ( $44 \%$ vs $21 \%$ ), depression ( $32 \%$ vs $20 \%$ ), and osteoporosis (26\% vs $9 \%$ ). Among the survey respondents, $87 \%$ of those with $0-1$ comorbidity but only $77 \%$ of those with $\geq 8$ comorbidities were treated by rheumatologists. Increasing numbers of comorbidities were associated with poorer values for TJC, SJC, function, and WHO-5.

Conclusion. Compared to a matched population, persons with RA present with increased prevalence of numerous comorbidities. Patients with RA and multimorbidity are at risk of insufficient rheumatological care and poorer patient-reported outcomes. (First Release January 15 2019; J Rheumatol 2019;46:564-71; doi:10.3899/jrheum.180668)

Key Indexing Terms: EPIDEMIOLOGY

HEALTHCARE

COMORBIDITY

DEPRESSION

RHEUMATOID ARTHRITIS

From the Department for Health Services Research, Carl von Ossietzky University, Oldenburg; Epidemiology, German Rheumatism Research Centre, Berlin; Department of Rheumatology and Clinical Immunology, Charité University Medicine Berlin, Berlin, Germany.

This study was supported by the German Federal Ministry of Education and Research (01EC1405).

A. Luque Ramos, MPH, Department for Health Services Research, Carl von Ossietzky University; I. Redeker, MSc, Epidemiology, German Rheumatism Research Centre; F. Hoffmann, Professor, Department for Health Services Research, Carl von Ossietzky University; J. Callhoff, MSc, Epidemiology, German Rheumatism Research Centre; A. Zink, Professor, Epidemiology, German Rheumatism Research Centre, and Department of Rheumatology and Clinical Immunology, Charité University Medicine Berlin; K. Albrecht, MD, Epidemiology, German Rheumatism Research Centre.

Address correspondence to A. Luque Ramos, Department for Health Services Research, Carl von Ossietzky University Oldenburg,

Ammerländer Heerstrasse 140, 26111 Oldenburg, Germany.

E-mail:andres.luque.ramos@uni-oldenburg.de

Accepted for publication October 4, 2018.
Comorbidity has become a focus of attention in rheumatoid arthritis (RA) in the past few years. RA patients are at increased risk of cardiovascular (CV) disease, serious infections, certain malignancies, and osteoporosis ${ }^{1,2}$. Because numerous comorbidities are often underrecognized, identification and subsequent care have been addressed in specific recommendations ${ }^{2,3,4}$. Higher comorbidity rates compared to previous decades, such as those reported from Finland, may already contribute to increased attention and diagnosis ${ }^{5}$. The widely noted COMORA study examined the prevalence of selected comorbidities in 17 participating countries worldwide ${ }^{1}$. The most frequently reported disorders were depression, asthma, and CV events. These data refer to a questionnaire provided by rheumatologists during a rheumatologic visit in each participating country. The strength of the data is the identification of large variability regarding comor-

Personal non-commercial use only. The Journal of Rheumatology Copyright $\odot$ $)$ 2019. All rights reserved 
bidity diagnoses and management. The questionnaire also enabled the investigation of the association of comorbidity prevalence with disease outcome variables ${ }^{6}$. However, prevalence should not be regarded as representative for patients with RA in each participating country. To determine prevalence and healthcare of comorbidities on a population-based level, it is necessary to study nationwide samples including persons without rheumatologic care, and to contrast the data with a sample without RA that is comparable in healthcare, age, and sex. Using this approach, an increased prevalence and incidence of psychiatric disorders in persons with RA was observed in a recent analysis of Canadian administrative claims data ${ }^{7}$.

The aim of our study was to investigate the prevalence of selected comorbidities in persons with RA in comparison to age- and sex-matched persons without RA and to study the association of comorbidity with rheumatologic care and with self-reported RA outcomes.

\section{MATERIALS AND METHODS}

Data source. We used data of the research network PROCLAIR (Linking Patient-Reported Outcomes with CLAIms data for health services Research in rheumatology $)^{8}$. Based on claims data of a German statutory health fund (BARMER) with 6.5 million members aged 18 to 79 years and continuously insured between 2012 and 2014, all outpatients diagnosed with RA [International Classification of Diseases, 10th ed (ICD-10) code M05.x or M06.x] in at least 2 quarters of the year 2013 were identified.

Claims data and matching. A set of 26 comorbidities (CV, endocrine, musculoskeletal, pulmonary, renal disorders, neoplasms, and depression) were selected by clinical relevance and by previous reports ${ }^{1,2}$. If at least 1 outpatient diagnostic code in 2015 was identified, the disease was assumed as prevalent. The respective ICD-10 codes are reported in the Appendix. They are based on the Elixhauser Comorbidity Index ${ }^{9}$ and augmented upon further relevant comorbidities for RA. A control group, consisting of all persons with an insurance period from 2012 up to 2014 and without RA diagnoses between 2012 and 2015, was matched by age and sex in a ratio of 1 to 5 . Prevalence of comorbidities in persons with RA were compared to this control group.

Drug prescriptions in 2015 were identified through the anatomical therapeutic chemical classification. To provide information on the proportion of treated depression, antidepressants (N06A) are reported.

Questionnaire data. In June 2015, a questionnaire on self-reported RA outcomes was sent to a random sample of 6193 persons with a diagnosis of RA, stratified by age group (18-49 yrs, 50-64 yrs, 65-79 yrs), sex (male, female), and diagnosis (M05, M06; 12 strata with 550 persons each). A reminder was sent out in August 2015. The questionnaire contained questions on healthcare, self-reported outcomes, disease activity, and effect of RA on social life ${ }^{8}$. Comprehensibility was assessed in a pre-test with a focus group of 8 patient partners from the German League against Rheumatism.

Tender and swollen joints were assessed by 50 and 48 joint counts for tenderness (tender joint count; TJC) and swelling (swollen joint count; SJC), respectively, in a patient-reported question/mannequin format ${ }^{10,11}$. Disability was assessed by the Hannover Functional Ability Questionnaire $(\mathrm{FFbH}$; range 0: no functional capacity, to 100 : full functional capacity) ${ }^{12}$. The effect of RA was ascertained by the RA Impact of Disease score (RAID; range 0: no impact, to 10: highest impact) ${ }^{13,14}$. The World Health Organization 5-item Well-being Index (WHO-5; scores transformed to 0-100) was used to determine the depressive symptoms based on the last 2 weeks. The depressive symptoms were categorized as mild (29-50) or moderate to severe (0-28), whereas patients scoring above 50 were considered to have no depressive symptoms ${ }^{15}$. Rheumatologic care (current, ever, year of first visit, distance from home of patient), smoking (current/former), height, and weight were self-reported. The latter were transformed to body mass index (BMI) in $\mathrm{kg} / \mathrm{m}^{2}$.

Analysis of RA cases and controls (claims data). Comorbidity prevalence in cases and controls are reported per 100 persons and with 95\% CI. Prevalence is reported by age groups (18-49 yrs, 50-64 yrs, 65-79 yrs), sex (male, female), and diagnosis (M05, M06).

Analysis of the random sample (linkage of claims and survey data). The total number of persons returning the questionnaires who gave their consent for linking questionnaire data to claims data was weighted according to the sex, age group, and diagnosis distribution of the source population. Weighted subgroup analyses were performed on those with self-reported confirmation of RA diagnosis. Descriptive statistics [mean, standard error of the mean (SEM), and percentages] were used to describe differences between the groups of persons with $0-1,2-4,5-7$, and $\geq 8$ comorbidities. The SEM was used instead of SD because of the stratified features of the study sample. Multivariable linear regression analyses were performed to analyze the effect of (1) the number of comorbidities (all 26 disorders were included), and (2) specific comorbidities (disorders with prevalence $>15 \%$ were included) on the patient-reported outcomes of SJC, TJC, FFbH, and WHO-5. Age, sex, BMI, smoking, and diagnosis (M05 or M06) were selected as covariates by clinical relevance. For the regression models, missing data were imputed using the fully conditional specification method with 10 imputations for each missing data value.

The study protocol was approved by the ethics committee of the Charité-Universitätsmedizin Berlin (EA1/051/15). All analyses were conducted with SAS, version 9.4 (SAS Institute Inc.) using procedures for complex survey designs (SURVEYMEANS, SURVEYFREQ, and SURVEYREG) for questionnaire data and using the procedures PROC MI and PROC MIANALYZE for multiple imputation.

\section{RESULTS}

Patient characteristics. A total of 96,921 persons with RA and 484,605 age- and sex-matched controls were included in the analyses (Figure 1). The mean age was 62.5 years and $79.6 \%$ were female. A total of $31.3 \%$ of the cases were hospitalized at least 1 time in 2015 , whereas $2.5 \%$ of the controls were admitted to a hospital.

Prevalence of comorbidities. The most frequent disorders in persons with RA were hypertension (HTN; 62.5\%), osteoarthritis (OA; 44.0\%), hyperlipidemia (39.9\%), depression (31.8\%), and osteoporosis (25.9\%). Except for osteoporosis, these conditions were also the most frequent diseases in controls. All comorbid conditions were more frequent in RA cases than in controls (Table 1). This applies in particular to osteoporosis (25.9\% vs 9.4\%), inflammatory bowel disease ( $2.3 \%$ vs $0.8 \%)$, OA ( $44.0 \%$ vs $21.4 \%)$, myocardial infarction ( $1.4 \%$ vs $0.8 \%)$, congestive heart failure $(10.3 \%$ vs $6.0 \%)$, renal failure (10.2\% vs $5.4 \%$ ), and depression $(31.8 \%$ vs $20.1 \%$ ). Of all persons with RA and depression, $43.4 \%$ were treated with any antidepressant.

The prevalence of all comorbidities in RA increased with age, except for asthma and inflammatory bowel disease (Table 2). While OA, osteoporosis, depression, hypothyroidism, asthma, venous thrombosis, and obesity were increased in females, $\mathrm{CV}$ disease, $\mathrm{CV}$ risk factors (except for obesity), and renal and liver disease were more frequent in males. The distribution of comorbid conditions was similar in seronegative (M06) and seropositive RA (M05), with the

Personal non-commercial use only. The Journal of Rheumatology Copyright $\odot$ 2019. All rights reserved. 


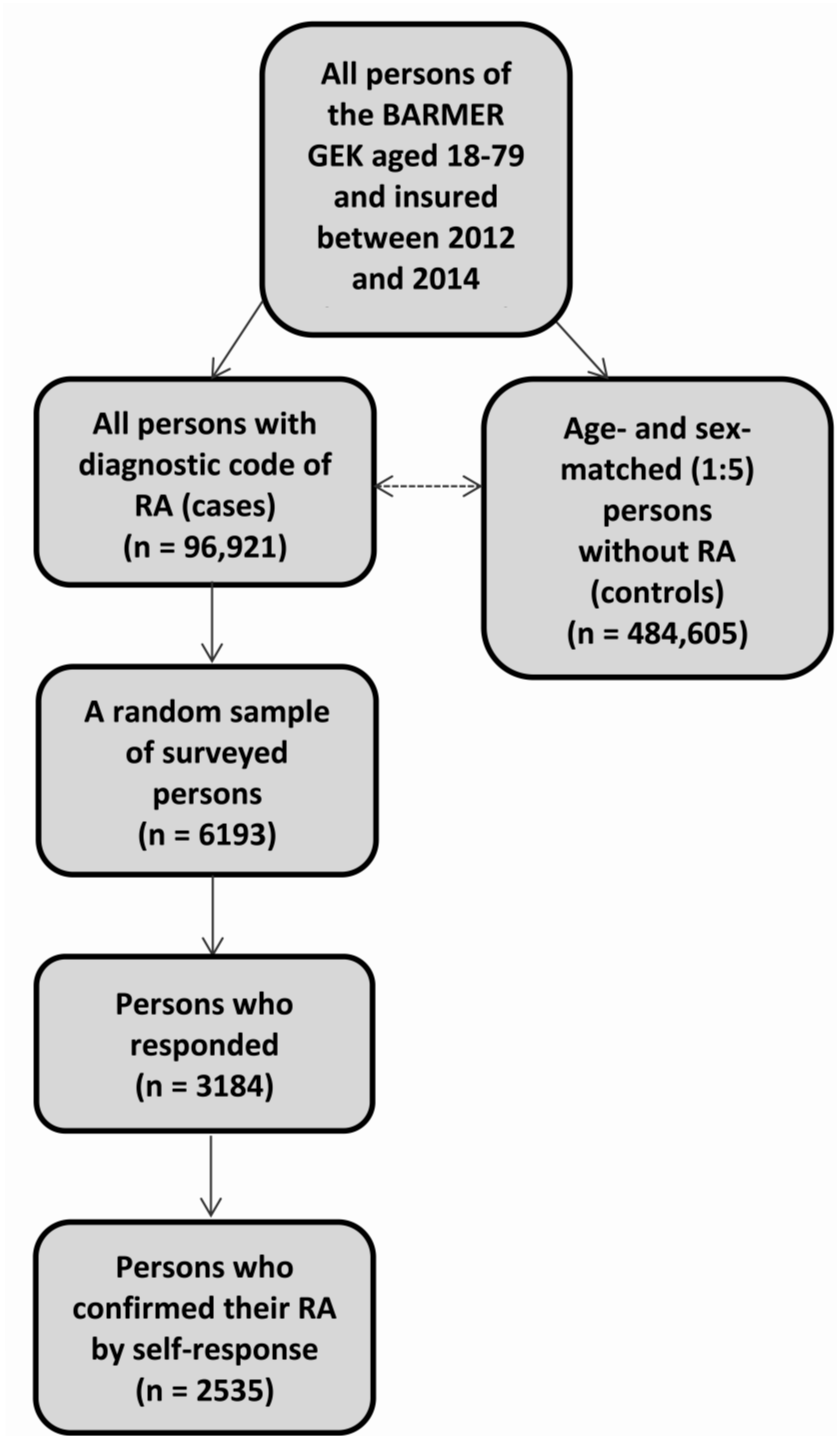

Figure 1. Flowchart of study population. RA: rheumatoid arthritis; BARMER GEK: German health insurance company.

exception of osteoporosis, which was more frequent in seropositive (31.3\%) than seronegative RA (24.0\%).

Comorbidity and patient-reported outcomes among survey respondents. From the random sample of 6600 persons with RA, a total of 6193 persons were still insured in 2015 and received the questionnaire. Of those, 3184 answered and 3140 gave their consent for linkage with claims data $(51.4 \%$ response). Only surveyed patients with self-reported confirmation of RA diagnosis $(n=2535)$ were included. A total of $49.9 \%$ of all respondents without self-confirmed RA $(n=605)$ reported another rheumatic disease and $32.2 \%$ no rheumatic disease. Of these, $17.9 \%$ gave no answer to this question. The most frequent self-reported diagnoses were OA $(\mathrm{n}=117)$, psoriatic arthritis $(\mathrm{n}=107)$, spondyloarthritis $(n=98)$, fibromyalgia $(n=87)$, and polymyalgia rheumatica
Table 1. Prevalence of selected comorbidities in RA cases and controls.

\begin{tabular}{|c|c|c|}
\hline Variables & $\begin{array}{c}\text { RA Cases } \\
(\mathrm{n}=96,921), \% \\
(95 \% \mathrm{CI})\end{array}$ & $\begin{array}{c}\text { Controls } \\
(\mathrm{n}=484,605), \% \\
(95 \% \mathrm{CI})\end{array}$ \\
\hline \multicolumn{3}{|l|}{ Cardiovascular disorders } \\
\hline Cardiac arrhythmia & $18.9(18.7-19.2)$ & $13.2(13.1-13.3)$ \\
\hline Congestive heart failure & $10.3(10.1-10.4)$ & $6.0(6.0-6.1)$ \\
\hline Coronary heart disease & $15.3(15.1-15.5)$ & $9.6(9.5-9.6)$ \\
\hline Myocardial infarction & $1.4(1.3-1.4)$ & $0.8(0.8-0.8)$ \\
\hline Stroke & $2.7(2.6-2.8)$ & $1.9(1.9-2.0)$ \\
\hline Valvular diseases & $10.9(10.7-11.1)$ & $7.1(7.0-7.2)$ \\
\hline Vascular diseases & $13.0(12.8-13.2)$ & $8.5(8.5-8.6)$ \\
\hline \multicolumn{3}{|l|}{ Thrombosis } \\
\hline Arterial thrombosis/embolism & $0.4(0.4-0.5)$ & $0.2(0.2-0.3)$ \\
\hline Venous thrombosis & $2.9(2.8-3.0)$ & $1.5(1.5-1.6)$ \\
\hline Pulmonary embolism & $1.1(1.0-1.1)$ & $0.5(0.5-0.5)$ \\
\hline \multicolumn{3}{|l|}{ Cardiovascular risk factors } \\
\hline Hypertension & $62.5(62.2-62.8)$ & $47.9(47.8-48)$ \\
\hline Hyperlipidemia & $39.9(39.6-40.2)$ & $32.3(32.2-32.5)$ \\
\hline Obesity & $18.0(17.8-18.2)$ & $12.2(12.1-12.3)$ \\
\hline \multicolumn{3}{|l|}{ Musculoskeletal diseases } \\
\hline Osteoarthritis & $44.0(43.7-44.3)$ & $21.4(21.2-21.5)$ \\
\hline Osteoporosis & $25.9(25.6-26.2)$ & $9.4(9.3-9.5)$ \\
\hline \multicolumn{3}{|l|}{ Neoplasms } \\
\hline Lymphoma & $1.0(1-1.1)$ & $0.6(0.6-0.6)$ \\
\hline Metastatic cancer & $1.7(1.7-1.8)$ & $1.4(1.4-1.5)$ \\
\hline Solid tumor without metastasis & $13.9(13.6-14.1)$ & $11.4(11.4-11.5)$ \\
\hline \multicolumn{3}{|c|}{ Pulmonary diseases } \\
\hline Asthma & $12.5(12.2-12.7)$ & $7.3(7.2-7.3)$ \\
\hline \multicolumn{3}{|c|}{ Chronic obstructive pulmonary } \\
\hline disease & $11.3(11.1-11.5)$ & $6.5(6.4-6.5)$ \\
\hline \multicolumn{3}{|l|}{ Other diseases } \\
\hline Depression & $31.8(31.5-32.1)$ & $20.1(20.0-20.3)$ \\
\hline Diabetes & $21.7(21.4-21.9)$ & $15.2(15.1-15.3)$ \\
\hline Hypothyroidism & $18.1(17.9-18.4)$ & $12.8(12.7-12.9)$ \\
\hline Inflammatory bowel disease & $2.3(2.2-2.4)$ & $0.8(0.8-0.9)$ \\
\hline Liver disease & $13.9(13.7-14.2)$ & $9.0(8.9-9.0)$ \\
\hline Renal failure & $10.2(10.0-10.4)$ & $5.4(5.4-5.5)$ \\
\hline
\end{tabular}

RA: rheumatoid arthritis.

$(\mathrm{n}=36)$. Compared to respondents with self-confirmed RA, respondents without self-confirmed RA were 2.4 years younger and more frequently male (19.6\% vs $23.4 \%)$.

Of this sample, $16.5 \%$ had $0-1,42.8 \%$ had $2-4,29.6 \%$ had $5-7$, and $11.1 \%$ had $\geq 8$ comorbidities (Table 3). The proportion of females (79.4\% in all respondents with RA) was comparable between the groups (80.0-82.3\%), except for patients with $\geq 8$ comorbidities ( $73.6 \%$ females). The mean age (62.8 yrs in all respondents with RA) increased with the number of comorbidities from 53.4 years in group $1(0-1$ comorbidity) to 72.9 years in group 4 ( $\geq 8$ comorbidities).

All variables obtained from questionnaire data had a maximum of $3 \%$ missing values, except for the variables TJC (10\% missing values), SJC (23\% missing values), and rheumatologic care (11\%). Mean SJC and TJC increased with the number of comorbidities (SJC from 5.1 to 9.2, and TJC from 9.5 to 15.7 ), while the proportion of patients with RA in rheumatologic care decreased (from $86.6 \%$ to $76.7 \%$ ) with 
Table 2. Prevalence of selected comorbidities in RA cases $(n=96,921)$, stratified by age, sex, and autoantibodies in percent.

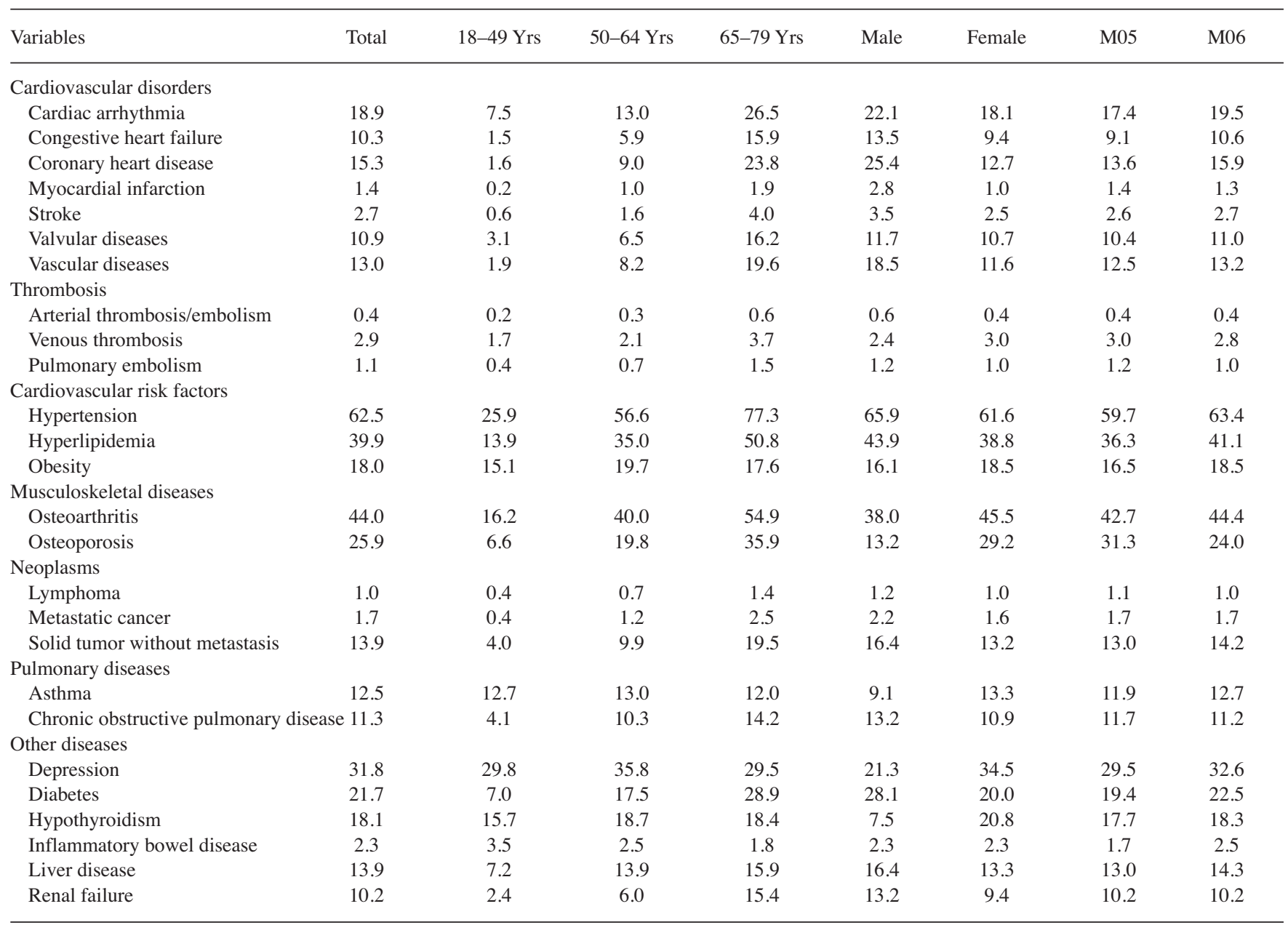

RA: rheumatoid arthritis; M05: seropositive RA, M06: seronegative RA.

increasing number of comorbidities. The proportion of RA patients with at least 1 admission to a hospital increased from $17.3 \%$ in group 1 ( $0-1$ comorbidity) up to $55.0 \%$ in group 4 ( $\geq 8$ comorbidities).

Association between comorbidity and patient-reported outcomes. In the multivariable linear regression model for the effect of the number of comorbidities on self-reported outcomes, mean SJC and TJC scores increased by 0.4 and 0.7 units, and WHO-5 and FFbH worsened by 1.9 and 2.3 units per additional comorbidity. BMI and female sex were also significantly associated with worse outcomes (BMI with WHO-5 and FFbH, but not with SJC and TJC; Table 4, Model A). When the number of comorbidities was replaced by the single disorders in a second model, depression and OA were significantly associated with worse TJC. OA and female sex were associated with increased SJC. Osteoporosis, OA, and depression were also significantly associated with worse $\mathrm{FFbH}$ values in addition to age, BMI, and female sex. HTN, depression, BMI, smoking, female sex, and age were associated with worse WHO-5 scores (Table 4, Model B).

\section{DISCUSSION}

This study of claims data linked to a survey of self-reported RA outcomes provides data on the prevalence and effect of comorbidities in persons with RA in Germany. Compared to population controls, a higher proportion of all selected comorbidities was found. The most striking difference between persons with RA and controls was observed for osteoporosis, but $\mathrm{CV}$ risk factors, $\mathrm{OA}$, and depression were also substantially more frequent in RA. Both the total numbers and specific comorbidities were associated with worse self-reported outcomes. Depression had the highest association with the reported functional status and TJC, but no single comorbidity had a clinically relevant influence on any of the self-reported outcomes. Of note, the proportion of patients with RA in rheumatologic care decreased with increasing numbers of comorbidities.

With a mean age of 62.5 years, this RA sample has a high proportion of older persons. The mean age is 7 years higher than in the COMORA cohort ${ }^{1}$, but it is comparable to rheumatologically treated patients with RA in the national

Personal non-commercial use only. The Journal of Rheumatology Copyright $\odot$ 2019. All rights reserved. 
Table 3. Characteristics of persons with RA in the random sample drawn from claims data $(\mathrm{n}=2535)$, stratified by number of comorbidities.

\begin{tabular}{lccccc}
\hline Characteristics & \multicolumn{5}{c}{ No. Comorbidities } \\
& $\begin{array}{c}0-1, \mathrm{n}=604 \\
(16.5 \%)\end{array}$ & $\begin{array}{c}2-4, \mathrm{n}=1060 \\
(42.8 \%)\end{array}$ & $\begin{array}{c}5-7, \mathrm{n}=632 \\
(29.6 \%)\end{array}$ & $\begin{array}{c}\geq 8, \mathrm{n}=239 \\
(11.1 \%)\end{array}$ & $\begin{array}{c}\text { Total, } \mathrm{n}=2535 \\
(100 \%)\end{array}$ \\
\hline Female sex & 80.0 & 82.3 & 80.6 & 73.6 & 80.4 \\
$18-49$ yrs & 33.9 & 9.5 & 2.5 & 0.7 & 10.5 \\
$50-64$ yrs & 49.0 & 39.0 & 24.9 & 11.4 & 33.4 \\
65-79 yrs & 17.1 & 51.5 & 72.6 & 87.9 & 56.1 \\
Seropositive & 36.7 & 31.8 & 28.4 & 26.9 & 31.1 \\
Rheumatologic care & 86.6 & 78.3 & 78.9 & 76.7 & 79.7 \\
BMI $\geq 30 \mathrm{~kg} / \mathrm{m}^{2}$ & 9.1 & 21.1 & 23.6 & 32.0 & 21.0 \\
Smoking, never & 56.6 & 66.9 & 64.3 & 68.5 & 64.6 \\
SJC (0-48), mean \pm SEM & $5.1 \pm 0.4$ & $7.9 \pm 0.5$ & $8.9 \pm 0.7$ & $9.2 \pm 1.0$ & $7.8 \pm 0.3$ \\
TJC (0-50), mean \pm SEM & $9.5 \pm 0.6$ & $12.6 \pm 0.5$ & $13.6 \pm 0.7$ & $15.7 \pm 1.1$ & $12.7 \pm 0.3$ \\
No. disorders, mean \pm SEM & $0.6 \pm 0.0$ & $3 \pm 0.0$ & $5.9 \pm 0.0$ & $9.4 \pm 0.1$ & $4.2 \pm 0.1$ \\
$\geq 1$ admission to hospital & 17.3 & 26.3 & 38.5 & 55.0 & 31.6 \\
\hline
\end{tabular}

Values are in \% unless otherwise indicated. RA: rheumatoid arthritis; BMI: body mass index, TJC: self-reported tender joint count; SJC: self-reported swollen joint count; SEM: standard error of the mean.

Table 4. Results from multivariable linear regression analyses. Association between comorbidities and patient-reported outcomes in the random sample $(\mathrm{n}=2535)$.

\begin{tabular}{|c|c|c|c|c|}
\hline \multirow[t]{2}{*}{ Variables } & \multicolumn{4}{|c|}{ Estimates ( $\mathrm{p}$ value) } \\
\hline & $\operatorname{SJC}(0-48)$ & TJC (0-50) & WHO-5 & $\mathrm{FFbH}$ \\
\hline \multicolumn{5}{|c|}{ Model A: association between no. comorbidities and outcomes } \\
\hline Comorbidities, per unit & $0.37(\mathbf{0 . 0 0 2 3})$ & $0.65(<\mathbf{0 . 0 0 0 1 )}$ & $-1.87(<\mathbf{0 . 0 0 0 1 )}$ & $-2.30(<\mathbf{0 . 0 0 0 1})$ \\
\hline BMI, per 5 units & $0.44(0.1294)$ & $0.45(0.1701)$ & $-1.43(\mathbf{0 . 0 2 6 0 )}$ & $-2.91(<\mathbf{0 . 0 0 0 1})$ \\
\hline Age, per 5 yrs & $0.16(0.1914)$ & $-0.02(0.8780)$ & $1.46(<\mathbf{0 . 0 0 0 1})$ & $-0.63(\mathbf{0 . 0 1 6 1 )}$ \\
\hline Seronegative RA & $-0.12(0.7998)$ & $0.26(0.6400)$ & $-0.51(0.6600)$ & $1.93(0.0679)$ \\
\hline Female sex & $1.56(\mathbf{0 . 0 0 5 0 )}$ & $1.32(\mathbf{0 . 0 2 6 5 )}$ & $-3.9(\mathbf{0 . 0 0 1 1})$ & $-7.34(<\mathbf{0 . 0 0 0 1})$ \\
\hline Smoking & $1.06(0.2346)$ & $0.8(0.4333)$ & $-6.54(\mathbf{0 . 0 0 0 2})$ & $-2.44(0.1055)$ \\
\hline \multicolumn{5}{|c|}{ Model B: association between specific comorbidities and outcomes } \\
\hline Cardiac arrhythmia & $0.25(0.7626)$ & $0.56(0.5472)$ & $0.04(0.9843)$ & $-1.12(0.5332)$ \\
\hline Coronary heart disease & $-0.01(0.9874)$ & $0.49(0.6563)$ & $-2.98(0.1720)$ & $-0.67(0.7355)$ \\
\hline Hypertension & $-0.23(0.7531)$ & $-0.04(0.9632)$ & $-3.14(\mathbf{0 . 0 3 9 2})$ & $-2.06(0.1493)$ \\
\hline Hyperlipidemia & $1.05(0.0982)$ & $1.20(0.0941)$ & $-0.68(0.6328)$ & $-0.56(0.6673)$ \\
\hline Hypothyroidism & $0.39(0.6062)$ & $-0.13(0.8733)$ & $-0.70(0.6779)$ & $-1.80(0.2536)$ \\
\hline Diabetes & $1.25(0.1509)$ & $1.25(0.1818)$ & $-2.57(0.1594)$ & $-3.01(0.0682)$ \\
\hline Osteoporosis & $0.33(0.6352)$ & $1.56(0.0523)$ & $-0.04(0.9808)$ & $-5.97(<\mathbf{0 . 0 0 0 1})$ \\
\hline Osteoarthritis & 1.27 (0.0292) & $1.43(\mathbf{0 . 0 3 5 0})$ & $-2.44(0.0723)$ & -4.51 (0.0002) \\
\hline Depression & $1.11(0.0917)$ & $2.66(\mathbf{0 . 0 0 0 2})$ & $-12.96(<\mathbf{0 . 0 0 0 1})$ & $-7.24(<\mathbf{0 . 0 0 0 1})$ \\
\hline BMI, per 5 units & $0.51(0.0951)$ & $0.63(0.0618)$ & $-1.45(\mathbf{0 . 0 2 8 6})$ & $-3.48(<\mathbf{0 . 0 0 0 1})$ \\
\hline Age, per 5 yrs & $0.18(0.1520)$ & $0.00(0.9819)$ & 1.08 (0.0004) & -0.97 (0.0005) \\
\hline Seronegative RA & $0.02(0.9693)$ & $0.25(0.6690)$ & $0.3(0.7904)$ & $1.86(0.0793)$ \\
\hline Female sex & 1.37 (0.0126) & $0.72(0.2805)$ & $-2.61(\mathbf{0 . 0 4 0 3})$ & $-5.08(<\mathbf{0 . 0 0 0 1})$ \\
\hline Smoking & $1.13(0.2216)$ & $0.71(0.4643)$ & $-5.63(\mathbf{0 . 0 0 0 5})$ & $-2.37(0.1093)$ \\
\hline
\end{tabular}

Values in bold face show statistically significant influence. Only comorbidities with prevalence above $15 \%$ were included in the second model. Although obesity had a prevalence above $15 \%$, this comorbidity was not included because of the selection of BMI. SJC: swollen joint count; TJC: tender joint count; WHO-5: World Health Organization 5-item Well-being Index; FFbH: Hannover Functional Ability Questionnaire; RA: rheumatoid arthritis; BMI: body mass index.

database (NDB) of the German Collaborative Arthritis Centers ${ }^{16}$. The age distribution partly explains the high prevalence of all comorbid conditions. For better comparison with data from other cohorts, prevalence was also reported for age and sex groups.

In addition to $\mathrm{CV}$ risk factors, $\mathrm{OA}$ was the most common 
comorbidity, being prevalent in $44 \%$ of persons with RA and twice as frequent compared to controls. OA is not reported in COMORA and self-reported in $15 \%$ of patients with RA in the Quest-RA study ${ }^{1,17}$. As a primary comorbidity as well as secondarily originating from RA, OA can be expected to be frequent in persons with RA. Attention to OA as a comorbidity in RA should be increased because it affects joint counts and functional status by its characteristics, especially in longstanding RA.

According to the claims data, depression was among the most frequent comorbid disorders, documented in almost one-third of patients with RA. In other cohorts, depression was reported in 15-39\% of patients, depending on the definition and age of the sample ${ }^{18}$. Taking into account the age distribution of the present sample, a large discrepancy remains with all rheumatologist-reported data from the German RA cohorts. In the early arthritis cohort CAPEA, the biologics registry RABBIT, and the NDB, depression has been reported in up to only $6 \%$ of patients with $\mathrm{RA}^{16}$. In the present cohort, as previously published, $49.7 \%$ of patients with RA reported any depressive symptoms and 25.5\% reported severe symptoms ${ }^{15}$, supporting a correct claims diagnosis. If considering only patients who were prescribed antidepressants, the proportion remains higher than observed in the RA cohorts so far. The results of the regression analyses underline that it is highly important to recognize concomitant depression in RA because it has a great influence not only on self-reported outcomes, as observed in our data, but also on remission rates and treatment success ${ }^{19}$. Thus, more comprehensive identification of depression in RA is an urgent unmet need. Recommendations to implement screening tools in rheumatologic care already exist ${ }^{20}$.

Osteoporosis has a unique position as a comorbidity in RA. In our present study, osteoporosis was also among the most common disorders; it was more frequent in women and in seropositive RA, and was 2.8 times more frequent in persons with RA compared to controls. More attention may be paid to diagnosing osteoporosis in RA compared to controls. A single-center study from the United Kingdom with comparable age and sex distribution reported a similar prevalence (29.9\%) for patients with RA as observed in the present analysis ${ }^{21}$. In the study from the UK, osteoporosis was validated with dual energy X-ray absorptiometry examination. Controls in the UK had a prevalence of $17.4 \%$. This suggests for our study underdiagnosis in controls rather than false-positive diagnoses in RA. In contrast to depression, osteoporosis has been recognized for many years as a relevant comorbidity in rheumatology 22 .

$\mathrm{CV}$ risk factors and $\mathrm{CV}$ disease are known to be increased in RA, but reported prevalence differs according to differences in age, region, and diagnostics ${ }^{1,23,24,25}$. In the current data from PROCLAIR, risk factors are highly frequent and outnumber the rheumatologist-documented CV risk in the German RA cohorts ${ }^{16}$. These results are in line with data from
ESCAPE and MESA, which measured CV risk factors in patients with RA and controls with a mean age of 60 years ${ }^{24}$. In our study, $57 \%$ of patients with RA and $42 \%$ of controls had HTN, and 51\% versus $45 \%$ had higher cholesterol levels. Of these, around one-quarter were previously undiagnosed ${ }^{24}$. In contrast to the data from COMORA ${ }^{6}$, hyperlipidemia was associated with increased SJC in our cohort. The risk of venous thrombosis and pulmonary embolism was about double in patients with RA compared to controls, which is in agreement with the results of a systematic review ${ }^{26}$ and a population-based cohort study 27 .

Considering other comorbidities, cardiac arrhythmia and hypothyroidism should also be acknowledged as frequent disorders, because they affect almost one-fifth of patients with RA. The presence of hypothyroidism has been reported to affect treatment response in the DANBIO registry ${ }^{28}$. In our results, hypothyroidism was not associated with any patientreported outcomes.

A previous analysis from PROCLAIR on diabetes in persons with RA indicated a low frequency of rheumatologic care in persons having concurrent RA and diabetes ${ }^{8}$. This observation was confirmed to be of relevance also for comorbidity in general. One would expect that persons with RA and a high number of comorbidities are more in need of specialized rheumatologic care because of the increased risk of drug interactions and other complications. However, these patients seem to slip off with less treatment, and reasons for this remain unclear ${ }^{8}$. One explanation may be that with more comorbidity, the relative importance of RA for the patient may decrease, and thus it seems more appropriate to stay with 1 physician who takes care of the various disorders.

A limitation of our study is the lack of clinical validation of diagnoses in claims data. However, in the subpopulation of surveyed patients with RA, only persons with the ICD code for RA and self-confirmed RA diagnosis were included. To consider the lacking validation, we reported the percentages of antidepressants for depression, expecting a more robust diagnosis if a medical treatment was prescribed. The cross-sectional design of the survey does not allow analysis of causality between comorbidity and self-reported outcomes. Diagnoses and prescriptions were from 2015, but our cohort had to be insured only until the end of 2014. However, nearly all cases and controls (98.9\% and $97.0 \%$ ) were also insured continuously in 2015 and including only them did not alter our findings. In some strata, SJC and TJC were not normally distributed. However, most patient-reported outcomes were normally distributed (WHO-5, FFbH, and some strata of SJC and TJC). Because we prefer a consistent approach, we used a linear multivariable regression for all outcomes.

The main strength of using claims data is the large number of persons with RA and controls with the same background of healthcare supply. This enables population-based analyses of healthcare, which is not possible with cohorts from rheumatology. The linkage of claims data with a survey that

Personal non-commercial use only. The Journal of Rheumatology Copyright $\subset$ 2019 . All rights reserved. 
was developed specifically for persons with RA enabled analysis of the effect of the observed comorbidity on RA-specific outcomes.

Persons with RA present with a higher level of comorbidity compared to controls. In addition to CV risk factors, among the most common comorbidities in RA are OA, depression, and osteoporosis. These disorders are associated with all patient-reported outcomes. Future research should address the problem of decreasing coverage by rheumatologic care with an increasing number of comorbidities.

\section{ACKNOWLEDGMENT}

The authors thank all patients and investigators who participated in our study, as well as BARMER for providing the data.

\section{REFERENCES}

1. Dougados M, Soubrier M, Antunez A, Balint P, Balsa A, Buch M, et al. Prevalence of comorbidities in rheumatoid arthritis and evaluation of their monitoring: results of an international, cross-sectional study (COMORA). Ann Rheum Dis 2014;73:62-8.

2. Roubille C, Richer V, Starnino T, McCourt C, McFarlane C, Fleming $\mathrm{P}$, et al. Evidence-based recommendations for the management of comorbidities in rheumatoid arthritis, psoriasis, and psoriatic arthritis: expert opinion of the Canadian

Dermatology-Rheumatology Comorbidity Initiative. J Rheumatol 2015;42:1767-80.

3. van Assen S, Agmon-Levin N, Elkayam O, Cervera R, Doran MF, Dougados $\mathrm{M}$, et al. EULAR recommendations for vaccination in adult patients with autoimmune inflammatory rheumatic diseases. Ann Rheum Dis 2011;70:414-22.

4. Peters MJ, Symmons DP, McCarey D, Dijkmans BA, Nicola P, Kvien TK, et al. EULAR evidence-based recommendations for cardiovascular risk management in patients with rheumatoid arthritis and other forms of inflammatory arthritis. Ann Rheum Dis 2010;69:325-31.

5. Uutela T, Kautiainen H, Järvenpää S, Salomaa S, Hakala M, Häkkinen A. Patients with rheumatoid arthritis have better functional and working ability but poorer general health and higher comorbidity rates today than in the late 1990s. Scand J Rheumatol 2015;44:173-81.

6. Crepaldi G, Scirè CA, Carrara G, Sakellariou G, Caporali R, Hmamouchi I, et al. Cardiovascular comorbidities relate more than others with disease activity in rheumatoid arthritis. PLoS One 2016;11:e0146991.

7. Marrie RA, Hitchon CA, Walld R, Patten SB, Bolton JM, Sareen J, et al; Canadian Institutes of Health Research Team in Defining the Burden and Managing the Effects of Psychiatric Comorbidity in Chronic Immunoinflammatory Disease. Increased burden of psychiatric disorders in rheumatoid arthritis. Arthritis Care Res 2018; 70:970-8.

8. Albrecht K, Luque Ramos A, Hoffmann F, Redeker I, Zink A. High prevalence of diabetes in patients with rheumatoid arthritis: results from a questionnaire survey linked to claims data. Rheumatology 2018;57:329-36.

9. Quan H, Sundararajan V, Halfon P, Fong A, Burnand B, Luthi JC, et al. Coding algorithms for defining comorbidities in ICD-9-CM and ICD-10 administrative data. Med Care 2005;43:1130-9.

10. Cheung PP, Ruyssen-Witrand A, Gossec L, Paternotte S, Le Bourlout C, Mazieres M, et al. Reliability of patient self-evaluation of swollen and tender joints in rheumatoid arthritis: a comparison study with ultrasonography, physician, and nurse assessments. Arthritis Care Res 2010;62:1112-9.
11. Barton JL, Criswell LA, Kaiser R, Chen YH, Schillinger D. Systematic review and metaanalysis of patient self-report versus trained assessor joint counts in rheumatoid arthritis. J Rheumatol 2009;36:2635-41.

12. Lautenschlaeger J, Mau W, Kohlmann T, Raspe HH, Struve F, Brückle $\mathrm{W}$, et al. [Comparative evaluation of a German version of the Health Assessment Questionnaire and the Hannover Functional Capacity Questionnaire]. [Article in German] Z Rheumatol 1997;56:144-55.

13. Gossec L, Paternotte S, Aanerud GJ, Balanescu A, Boumpas DT, Carmona $\mathrm{L}$, et al. Finalisation and validation of the rheumatoid arthritis impact of disease score, a patient-derived composite measure of impact of rheumatoid arthritis: a EULAR initiative. Ann Rheum Dis 2011;70:935-42.

14. Dougados M, Brault Y, Logeart I, van der Heijde D, Gossec L, Kvien T. Defining cut-off values for disease activity states and improvement scores for patient-reported outcomes: the example of the Rheumatoid Arthritis Impact of Disease (RAID). Arthritis Res Ther 2012;14:R129.

15. Jobski K, Luque Ramos A, Albrecht K, Hoffmann F. Pain, depressive symptoms and medication in German patients with rheumatoid arthritis-results from the linking patient-reported outcomes with claims data for health services research in rheumatology (PROCLAIR) study. Pharmacoepidemiol Drug Saf 2017;26:766-74.

16. Albrecht K. [Gender-specific differences in comorbidities of rheumatoid arthritis]. [Article in German] Z Rheumatol 2014;73:607-14

17. Grøn KL, Ornbjerg LM, Hetland ML, Aslam F, Khan NA, Jacobs JW, et al. The association of fatigue, comorbidity burden, disease activity, disability and gross domestic product in patients with rheumatoid arthritis. Results from 34 countries participating in the Quest-RA program. Clin Exp Rheumatol 2014;32:869-77.

18. Matcham F, Rayner L, Steer S, Hotopf M. The prevalence of depression in rheumatoid arthritis: a systematic review and meta-analysis. Rheumatology 2013;52:2136-48.

19. Michelsen B, Kristianslund EK, Sexton J, Hammer HB, Fagerli $\mathrm{KM}$, Lie E, et al. Do depression and anxiety reduce the likelihood of remission in rheumatoid arthritis and psoriatic arthritis? Data from the prospective multicentre NOR-DMARD study. Ann Rheum Dis 2017;76:1906-10.

20. Withers MH, Gonzalez LT, Karpouzas GA. Identification and treatment optimization of comorbid depression in rheumatoid arthritis. Rheumatol Ther 2017;4:281-91

21. Hauser B, Riches PL, Wilson JF, Horne AE, Ralston SH. Prevalence and clinical prediction of osteoporosis in a contemporary cohort of patients with rheumatoid arthritis. Rheumatology 2014;53:1759-66.

22. Haugeberg G, Ørstavik RE, Uhlig T, Falch JA, Halse JI, Kvien TK. Clinical decision rules in rheumatoid arthritis: do they identify patients at high risk for osteoporosis? Testing clinical criteria in a population based cohort of patients with rheumatoid arthritis recruited from the Oslo Rheumatoid Arthritis Register. Ann Rheum Dis 2002;61:1085-9.

23. Radner H, Lesperance T, Accortt NA, Solomon DH. Incidence and prevalence of cardiovascular risk factors among patients with rheumatoid arthritis, psoriasis, or psoriatic arthritis. Arthritis Care Res 2017;69:1510-8

24. Chung CP, Giles JT, Petri M, Szklo M, Post W, Blumenthal RS, et al. Prevalence of traditional modifiable cardiovascular risk factors in patients with rheumatoid arthritis: comparison with control subjects from the multi-ethnic study of atherosclerosis. Semin Arthritis Rheum 2012;41:535-44.

25. Ruscitti P, Margiotta DP, Macaluso F, Iacono D, D’Onofrio F, Emmi $\mathrm{G}$, et al. Subclinical atherosclerosis and history of cardiovascular events in Italian patients with rheumatoid arthritis: Results from a 
cross-sectional, multicenter GIRRCS (Gruppo Italiano di Ricerca in Reumatologia Clinica e Sperimentale) study. Medicine 2017;96:e8180

26. Ungprasert P, Srivali N, Spanuchart I, Thongprayoon C, Knight EL. Risk of venous thromboembolism in patients with rheumatoid arthritis: a systematic review and meta-analysis. Clin Rheumatol 2014;33:297-304.

27. Chung WS, Peng CL, Lin CL, Chang JY, Chen JF, Chiang JY, et al Rheumatoid arthritis increases the risk of deep vein thrombosis and pulmonary thromboembolism: a nationwide cohort study. Ann Rheum Dis 2014;73:1774-80.

28. Emamifar A, Hangaard J, Jensen Hansen IM. Thyroid disorders in patients with newly diagnosed rheumatoid arthritis is associated with poor initial treatment response evaluated by disease activity score in 28 joints-C-reactive protein (DAS28-CRP): an observational cohort study. Medicine 2017;96:e8357.

APPENDIX 1. ICD-10 codes of the selected comorbidities.

\begin{tabular}{|c|c|}
\hline Comorbidities & ICD-10 \\
\hline Asthma & $\mathrm{J} 45$ \\
\hline Arterial thrombosis/embolism & $\mathrm{I} 74$ \\
\hline Cardiac arrhythmias & I44.1-I44.3, I45.6, I45.9, I47-I49, R00.0, R00.1, R00.8, T82.1, Z45.0, Z95.0 \\
\hline Congestive heart failure & $\mathrm{I} 09.9, \mathrm{I} 11.0, \mathrm{I} 13.0, \mathrm{I} 13.2, \mathrm{I} 25.5, \mathrm{I} 42.0, \mathrm{I} 42.5-\mathrm{I} 42.9, \mathrm{I} 43, \mathrm{I} 50, \mathrm{P} 29.0$ \\
\hline Coronary heart disease & I 25 \\
\hline COPD & $\mathrm{J} 44$ \\
\hline Depression & F20.4, F31.3-F31.5, F32, F33, F34.1, F41.2, F43.2 \\
\hline Diabetes & E10-E14 \\
\hline Hyperlipidemia & E78 \\
\hline Hypertension & I10-I13, I15 \\
\hline Hypothyroidism & E00-E03, E89.0 \\
\hline Inflammatory bowel disease & $\mathrm{K} 50, \mathrm{~K} 51, \mathrm{~K} 523$ \\
\hline Liver disease & $\begin{array}{l}\text { B18, I85, I86.4, I98.2, K70, K71.1, K71.3-K71.5, K71.7, K72-K74, K76.0, } \\
\text { K76.2-K76.9. Z94.4 }\end{array}$ \\
\hline Lymphoma & $\mathrm{C} 81-\mathrm{C} 85, \mathrm{C} 88, \mathrm{C} 90.0, \mathrm{C} 90.2, \mathrm{C} 96$ \\
\hline Metastatic cancer & $\mathrm{C} 77-\mathrm{C} 80$ \\
\hline Myocardial infarction & $\mathrm{I} 21, \mathrm{I} 22$ \\
\hline Obesity & E66 \\
\hline Osteoarthritis & M15-M17 \\
\hline Osteoporosis & M80-M82 \\
\hline Pulmonary embolism & I 26 \\
\hline Renal failure & I12.0, I13.1, N18, N19, N25.0, Z49.0-Z49.2, Z94.0, Z99.2 \\
\hline Solid tumor without metastasis & $\mathrm{C} 00-\mathrm{C} 26, \mathrm{C} 30-\mathrm{C} 34, \mathrm{C} 37-\mathrm{C} 41, \mathrm{C} 43, \mathrm{C} 45-\mathrm{C} 58, \mathrm{C} 60-\mathrm{C} 76, \mathrm{C} 97$ \\
\hline Stroke & I63, I64 \\
\hline Valvular disease & A52.0, I05-I08, I09.1, I09.8, I34-I39, Q23.0-Q23.3, Z95.2, Z95.4 \\
\hline Vascular disorders & $\begin{array}{l}\text { I70, I71, I73.1, I73.8, I73.9, I77.1, I79.0, I79.2, K55.1, K55.8, K55.9, Z95.8, } \\
\text { Z95.9 }\end{array}$ \\
\hline Venous thrombosis & I 80 \\
\hline
\end{tabular}

ICD-10: International Classification of Diseases, 10th ed; COPD: chronic obstructive pulmonary disease. 